\title{
Oligosaccharide concentrations in colostrum, transition milk, and mature milk of primi- and multiparous Holstein cows during the first week of lactation
}

\author{
A. J. Fischer-Tlustos, ${ }^{1}$ K. Hertogs,${ }^{2}$ J. K. van Niekerk, ${ }^{3}$ M. Nagorske, ${ }^{4}$ D. M. Haines,,${ }^{4,5}$ and M. A. Steele ${ }^{1,3 *}$ \\ ${ }^{1}$ Department of Animal Biosciences, Animal Science and Nutrition, University of Guelph, Guelph, ON, Canada N1G 1Y2 \\ ${ }^{2}$ Animal Nutrition Group, Department of Animal Science, Wageningen University \& Research, Wageningen 6708, the Netherlands \\ ${ }^{3}$ Department of Agricultural, Food and Nutritional Science, University of Alberta, Edmonton, AB, Canada T6G 2P5 \\ ${ }^{4}$ The Saskatoon Colostrum Company Ltd., Saskatoon, SK, Canada S7K 6A2 \\ ${ }^{5}$ Western College of Veterinary Medicine, University of Saskatchewan, Saskatoon, SK, Canada S7N 5B4
}

\section{ABSTRACT}

The objective of this study was to characterize the oligosaccharide (OS) profile of colostrum and transition milk from primiparous $(\mathrm{Pp}, \mathrm{n}=10)$ and multiparous $(\mathrm{Mp}, \mathrm{n}=10)$ Holstein cows. The experiment was conducted on a commercial dairy farm, where cows were assigned to the study at calving. Colostrum (milking 1) was collected at $5.3 \pm 0.7 \mathrm{~h}$ after parturition, followed by collection of milkings 2 through 6 , milkings 8 , 10, 12, and 14 at 0500 and $1600 \mathrm{~h}$ each day. Samples were analyzed for OS concentrations using liquid chromatography-mass spectrometry and for IgG and milk components. Concentration of $\operatorname{IgG}$ was highest in colostrum and milking 2. Colostral IgG concentration was less in $\mathrm{Pp}$ cows than in Mp cows (82.1 \pm 3.1 vs. $106.1 \pm 16.2 \mathrm{mg} / \mathrm{mL}$ ). Colostrum and milkings 2 and 3 had 3 '-sialyllactose and 6 -sialyllactose concentrations greater than those of mature milk (milkings $8+$ ). For colostrum and milking 2, 6'-sialyllactosamine concentrations were higher than all other milkings, while disialyllactose was only higher in colostrum. In addition, 3 '-sialyllactose was the most abundant OS in colostrum and milkings 2 and 3 compared with all other OS. A parity difference was observed for 6'-sialyllactosamine, with Mp having a higher concentration over the first 7 $\mathrm{d}$ in milk than $\operatorname{Pp}(46.4 \pm 8.7$ vs. $16.9 \pm 3.2 \mu \mathrm{g} / \mathrm{mL})$. Similar results were observed between milkings for OS yields. Parity differences were detected for 3 '-sialyllactose, 6'-sialyllactose, and 6'-sialyllactosamine yield, with Mp yield being greater than $\mathrm{Pp}$ over the first 7 $\mathrm{d}$ in milk. These findings demonstrate that colostrum and transition milk contain elevated concentrations of

Received July 30, 2019.

Accepted December 6, 2019.

*Corresponding author: masteele@uoguelph.ca certain OS compared with mature milk and suggest further research should be conducted regarding the potential benefits of OS in colostrum and transition milk when fed to newborn calves.

Key words: oligosaccharides, colostrum, transition milk, immunoglobulin G

\section{INTRODUCTION}

Bovine colostrum is a nutrient-dense substance that contains bioactive and immune factors essential to promoting the health and welfare of the young dairy calf (Blum and Hammon, 2000; Godden, 2008). The majority of colostrum research has focused on IgG content, as the passive transfer of $\operatorname{IgG}$ from colostrum is critical to calf survival and health (Godden, 2008). However, in addition to IgG, colostrum contains an abundance of bioactive molecules that are presumably tailored to support the development and maturation of the newborn calf. For instance, colostrum contains high concentrations of acidic oligosaccharides (OS; Martín-Sosa et al., 2003) that prevent pathogen adhesion to the intestinal epithelium (Martín et al., 2002; Sohanpal et al., 2004), may enhance the uptake of IgG (Gill et al., 1999), and serve as carbon sources for beneficial bacteria to promote their growth and establishment in the intestine (Yu et al., 2013; Fischer et al., 2018). In contrast to human milk OS, more than $70 \%$ of bovine colostrum and milk OS contains one or more acidic sialic acid residues, with the most abundant OS being sialyllactose [e.g., 3'-sialyllactose (3'SL), 6'-sialyllactose (6'SL), and disialyllactose (DSL)] and sialyllactosamine [e.g., 6'-sialyllactosamine (6'SLN) and $3^{\prime}$-sialyllactosamine (3'SLN)] (Martín-Sosa et al., 2003; Tao et al., 2008).

Recent research has demonstrated that gastrointestinal tract (GIT) disorders continue to be the most prominent illness in preweaning calves, with $17.2 \%$ of all calves displaying GIT clinical signs, which represented half $(50.9 \%)$ of all ill calves in a large-scale $(\mathrm{n}=$ 
2,545) US study (Urie et al., 2018). Naturally derived bovine OS secreted by the mammary gland, such as 3'SL, may promote a healthy gut environment in the neonatal calf (Short et al., 2016; Fischer et al., 2018). However, the concentrations of OS during the first week of lactation are largely uncharacterized because the majority of studies only collect single samples during early (Tao et al., 2008), mid-, and late lactation (Martín-Sosa et al., 2003; Tao et al., 2009; Fong et al., 2011). In addition, studies often have not standardized the timing of colostrum, or "first-milking," sample collection and use either a sample collected within hours of calving (Nakamura et al., 2003; Tao et al., 2008, 2009), at the second milking (Fong et al., 2011), or on d 2 of lactation (Martín-Sosa et al., 2003). Despite this variability among studies, research demonstrates that the concentrations of OS decrease rapidly from colostrum to mid-lactation milk (Martín-Sosa et al., 2003; Tao et al., 2008, 2009; Fong et al., 2011); however, research characterizing the concentrations of OS in transition milk (TM, milkings 2-6; Blum and Hammon, 2000) is lacking. Because studies have demonstrated feeding TM after the initial colostrum meal may have beneficial effects on calf gut development and health compared with calves fed whole milk (Conneely et al., 2014; Pyo et al., 2020), it is worthwhile to investigate specific compounds in TM, such as OS, that may provide benefits to calf health.

To our knowledge, the effect of parity on bovine colostrum and TM OS concentrations has not been studied because the majority of studies use only multiparous (Mp) cows (Martín-Sosa et al., 2003; Nakamura et al., 2003; Tao et al., 2008, 2009; Barile et al., 2010). In addition, the one study that examined both $\mathrm{Mp}$ and primiparous (Pp) cows (Sundekilde et al., 2012) only measured OS concentrations from 138 to 232 DIM and did not account for parity as a fixed effect in its statistical model. The possibility exists that increased bovine mammary gland development associated with increasing parity leads to upregulation of previously characterized glycosylation-related genes (Wickramasinghe et al., 2011). However, this idea is speculative because limited knowledge exists on the synthesis of OS in the bovine mammary gland (Wickramasinghe et al., 2011) and the possible effect of parity on OS concentrations has not been explored.

The objective of this study was to characterize the acidic OS profile during the first week of lactation in $\mathrm{Pp}$ and Mp Holstein cows. We hypothesized that the concentrations of OS would decline from colostrum to mature milk and Mp cows would have higher concentrations of acidic OS than Pp cows.

\section{MATERIALS AND METHODS}

\section{Sample Collection}

Experimental procedures were conducted in accordance with the Canadian Council of Animal Care (CCAC, 1993), and the University of Alberta Animal Care and Use Committee for Livestock approved all procedures (AUP 00002015). The experiment was conducted at Breevliet Farms Ltd. (Millet, AB, Canada) during May and June 2017. Twenty Holstein cows (Pp, $\mathrm{n}=10 ; \mathrm{Mp}, \mathrm{n}=10$ ) were assigned to the study at calving. The selected number of animals was determined from 3'SL concentrations in colostrum of Friesian cows $(\mathrm{n}=18$; McJarrow and van Amelsfort-Schoonbeek, 2004) to provide a power of 0.80 at a level of significance of 0.05 to detect a difference between parity. Multiparous cows (average parity, $3.1 \pm 0.4$ ) were dried off using Spectramast DC (Zoetis, Parsippany, NJ), and the average dry period length was $53.4 \pm 3.8 \mathrm{~d}$. Cows were group-housed and fed the same dry cow ration (Supplemental Table S1; https://doi.org/10.3168/jds .2019-17357) 3 wk before calving. Time of calving was recorded for each cow. No cows enrolled in the study displayed clinical signs of illness or received antibiotics during the 7-d sampling period, and all cows received the same lactation diet following calving (Supplemental Table S1).

All cows were milked twice daily at 0500 and 1600 h. The colostrum sample was taken at the first milking time following parturition $(5.3 \pm 0.7 \mathrm{~h}$ after parturition). Homogeneous colostrum and milk samples $(2 \times 15 \mathrm{~mL})$ were collected from the milking system (BouMatic, Madison, WI) over the first 7 DIM. Specifically, colostrum (milking 1 ) and milkings 2 through $6,8,10,12$, and 14 were collected. The samples were immediately snap frozen in liquid nitrogen and then transferred to a $-20^{\circ} \mathrm{C}$ freezer until OS analysis. An additional sample $(\sim 30 \mathrm{~mL})$ was collected and stored at $-20^{\circ} \mathrm{C}$ until it was sent to CanWest DHI testing laboratory (Central Milk Testing Laboratory, CanWest Dairy Herd Improvement, Edmonton, AB, Canada) to analyze fat, protein, lactose, SCC, MUN, and TS using mid-infrared spectroscopy (Milkoscan FT 6000; Foss, Hillerød, Denmark). In addition, a subset $(\sim 5 \mathrm{~mL})$ of the sample collected for milk component analysis was immediately frozen at $-20^{\circ} \mathrm{C}$, until it was shipped on ice to the Quality Assurance Laboratory of the Saskatoon Colostrum Co. Ltd. (Saskatoon, SK, Canada) overnight for determination of IgG concentration $(\mathrm{g} / \mathrm{L})$ by radial immunodiffusion analysis as described by Chelack et al. (1993). 


\section{Carbohydrate Fraction Isolation}

Colostrum, TM, and mature milk samples were thawed slowly at room temperature $\left(22^{\circ} \mathrm{C}\right)$. An aliquot $(1 \mathrm{~mL})$ of each sample was defatted by centrifugation $\left(6,000 \times g, 15 \mathrm{~min}, 22^{\circ} \mathrm{C}\right)$ and skim milk was diluted 1:4 with HPLC-grade water. Diluted skim milk was vortexed and thoroughly mixed with $1 \mathrm{~mL}$ of a $2: 1$ (vol/vol) chloroform:methanol solution. Subsamples $(500 \mu \mathrm{L})$ were centrifuged $\left(300 \times g, 60 \mathrm{~min}, 22^{\circ} \mathrm{C}\right)$ to precipitate the protein fraction and yield the upper (supernatant; carbohydrate fraction) and lower (protein fraction) phases of the remaining solution. The supernatant was transferred to a separate tube and stored at $4^{\circ} \mathrm{C}$, while the lower phase was re-extracted with $500 \mu \mathrm{L}$ of a $50 \%$ methanol solution and centrifuged at $300 \times g$ for $60 \mathrm{~min}$ at $22^{\circ} \mathrm{C}$. Both supernatant fractions were recombined and brought up to $1.5 \mathrm{~mL}$ with 95\% acetonitrile (AcN). Samples were then stored at $4^{\circ} \mathrm{C}$ for $40 \mathrm{~min}$, after which they were further purified by centrifugation at $11,000 \times g$ for $15 \mathrm{~min}$ at $22^{\circ} \mathrm{C}$. The supernatant was then collected and stored at $4^{\circ} \mathrm{C}$ until further analysis with liquid chromatography-mass spectrometry (LC-MS).

\section{LC-MS Analysis}

Five sialyloligosaccharide standards of known concentration were injected into the LC-MS apparatus to obtain calibration curves. Standards were $3^{\prime}$ SL, 6'SL, 3'SLN, 6'SLN, DSL and B1-3 gal- $N$-acetyl galactosaminyl-B1-4 gal-B1-4-Glc (internal standard), purchased from Dextra Laboratories Ltd. (Reading, UK). Oligosaccharide standards were prepared in HPLC-grade water to achieve a concentration of $1 \mathrm{mg} / \mathrm{mL}$. A 9-point calibration curve was obtained by diluting the OS standard solutions with $95 \%$ AcN. The internal standard was diluted from $1 \mathrm{mg} / \mathrm{mL}$ to $0.02 \mathrm{mg} / \mathrm{mL}$ and was mixed with the isolated carbohydrate fraction of each sample in an autosampler vial at an equal (1:1) volume before LC-MS analysis.

Oligosaccharides were separated by an LC-MS equipped with a binary pump and autosampler (Agilent Technologies, Palo Alto, CA) coupled to a 4000 QTRAP mass spectrometer (AB Sciex, Concord, ON, Canada) and Analyst 1.6 software to process the data. Separation was performed using an Ascentis Express HILIC column $(10 \mathrm{~cm} \times 2.1 \mathrm{~mm}, 2.7 \mu \mathrm{m}$ in particle size; Sigma, St. Louis, MO). The mobile phase consisted of both water plus $50 \mathrm{~m} M$ ammonium acetate and AcN. Processing conditions were adjusted as described by Fischer et al. (2018). Each sample, with a set injection volume of $5 \mu \mathrm{L}$, ran for $35 \mathrm{~min}$ in duplicate with a constant flow rate of $200 \mu \mathrm{L} / \mathrm{min}$, while the autosampler temperature was maintained at $15^{\circ} \mathrm{C}$. The electrospray ionization was used under negative ion mode for which a multiple reaction-monitoring scan was developed as described by Fischer et al. (2018) to quantify the compounds of interest. Nitrogen was used as curtain gas, nebulizing gas, and drying gas with 20, 50, and 50 arbitrary units, respectively. Ion source temperature was $400^{\circ} \mathrm{C}$ and voltage was set at $-4.5 \mathrm{kV}$.

\section{Statistical Analysis}

All data were analyzed as repeated measurements using the MIXED procedure of SAS software (version 9.4, SAS Institute Inc., Cary, NC). The model for yield, OS concentration, OS yield, all milk components, and IgG included the fixed effects of parity, milking (repeated), and the interaction of milking and parity and random effect of cow using the following model:

$$
Y_{i j k}=\mu+\text { milking }_{i}+\text { parity }_{j}+M P_{i j}+\varepsilon_{i j k},
$$

where $Y_{i j k}=$ the $k$ th observation in the $i$ th milking and $j$ th parity; $\mu=$ the overall mean; milking $_{i}=$ the fixed effect of the $i$ th milking; parity $_{j}=$ the fixed effect of the $j$ th parity; $M P_{i j}=$ the fixed effect of the interaction between the $i$ th milking and $j$ th parity; and $\varepsilon_{i j k}=$ the random error in the $k$ th observation in the ith milking and $j$ th parity. In order to determine the effect of OS type ( $\left.3^{\prime} \mathrm{SL}, 6^{\prime} \mathrm{SL}, 6^{\prime} \mathrm{SLN}, \mathrm{DSL}\right)$ on the OS concentration and yield, the following model was used:

$$
\begin{aligned}
Y_{i j k l}= & \mu+M_{i}+P_{j}+O S_{k}+(M \times P \times O S)_{i j k} \\
& +(M \times O S)_{i k}+(P \times O S)_{j k}+\varepsilon_{i j k l},
\end{aligned}
$$

where $Y_{i j k l}=$ the $l$ th observation in the $i$ th milking, $j$ th parity, and $k$ th OS type; $\mu=$ the overall mean; $M_{i}=$ the fixed effect of the $i$ th milking; $P_{j}=$ the fixed effect of the $j$ th parity; $O S_{k}=$ the fixed effect of the $k$ th OS type (e.g., 3'SL, 6'SL, DSL, 6'SLN, 3'SLN); $(M \times P \times$ $O S)_{i j k}=$ the fixed effect of the interaction between the $i$ th milking, jth parity, and $k$ th OS type; $(M \times O S)$ $i k=$ the fixed effect of the interaction between the $i$ th milking and $k$ th OS type; $(P \times O S)_{j k}=$ the fixed effect of the interaction between the $j$ th parity and $k$ th OS type; and $\varepsilon_{i j k l}=$ the random error in the lth observation in the $i$ th milking, $j$ th parity, and $k$ th OS type.

Tukey test was used to separate the least squares means (LSM). At least 3 variance-covariance structures were tested, and the covariance structure that had the lowest Schwarz's Bayesian information criterion was chosen. For both models, a compound symmetry covariance structure was used because the spacing from calving and subsequent milkings was unequal. All val- 
ues reported are $\mathrm{LSM} \pm \mathrm{SE}$, with significance declared at $P \leq 0.05$.

\section{RESULTS}

\section{Colostrum and Milk Components}

Parity affected yield, with Mp cows having a higher yield on average per milking over the first 7 DIM than Pp cows $(13.4 \pm 0.6$ vs. $9.8 \pm 0.3 \mathrm{~kg} /$ milking, $P<$ 0.0004; Figure 1A). Milking number had an effect on yield. Colostrum and milking 2 had an equivalent yield, and milking 4 onwards had a greater yield than colostrum and milking $2(P<0.0001$; Table 1$)$. In addition, Mp cows had a higher $(P<0.0001$; Figure $1 \mathrm{~A})$ yield during milkings 10,12 , and 14 than Pp cows, but not in colostrum $(P=1.0)$ or in milkings $2-6(P>0.39)$ or $8(P=0.07)$.

A difference was observed between $\mathrm{Pp}$ and $\mathrm{Mp}$ for SCC, with Mp cows having a higher $(P=0.007)$ SCC on average per milking over the first 7 DIM compared with $\mathrm{Pp}$ cows $\left[(1,609.5 \pm 199.0) \times 10^{3}\right.$ cells $/ \mathrm{mL}$ vs. $(562.5 \pm 88.5) \times 10^{3}$ cells $\left./ \mathrm{mL}\right]$. In addition, colostrum and milkings 2 and 3 had a higher SCC compared with milkings $8+(P<0.0001$; Table 1$)$. Moreover, Mp cows had a higher SCC in colostrum compared with Pp cows $(P=0.0002$; Table 2).

With regard to fat, $P p$ cows had a higher $(P=0.002)$ fat percentage on average per milking over the first 7 DIM than Mp cows $(4.9 \pm 0.1$ vs. $3.7 \pm 0.1 \%)$. Colos-
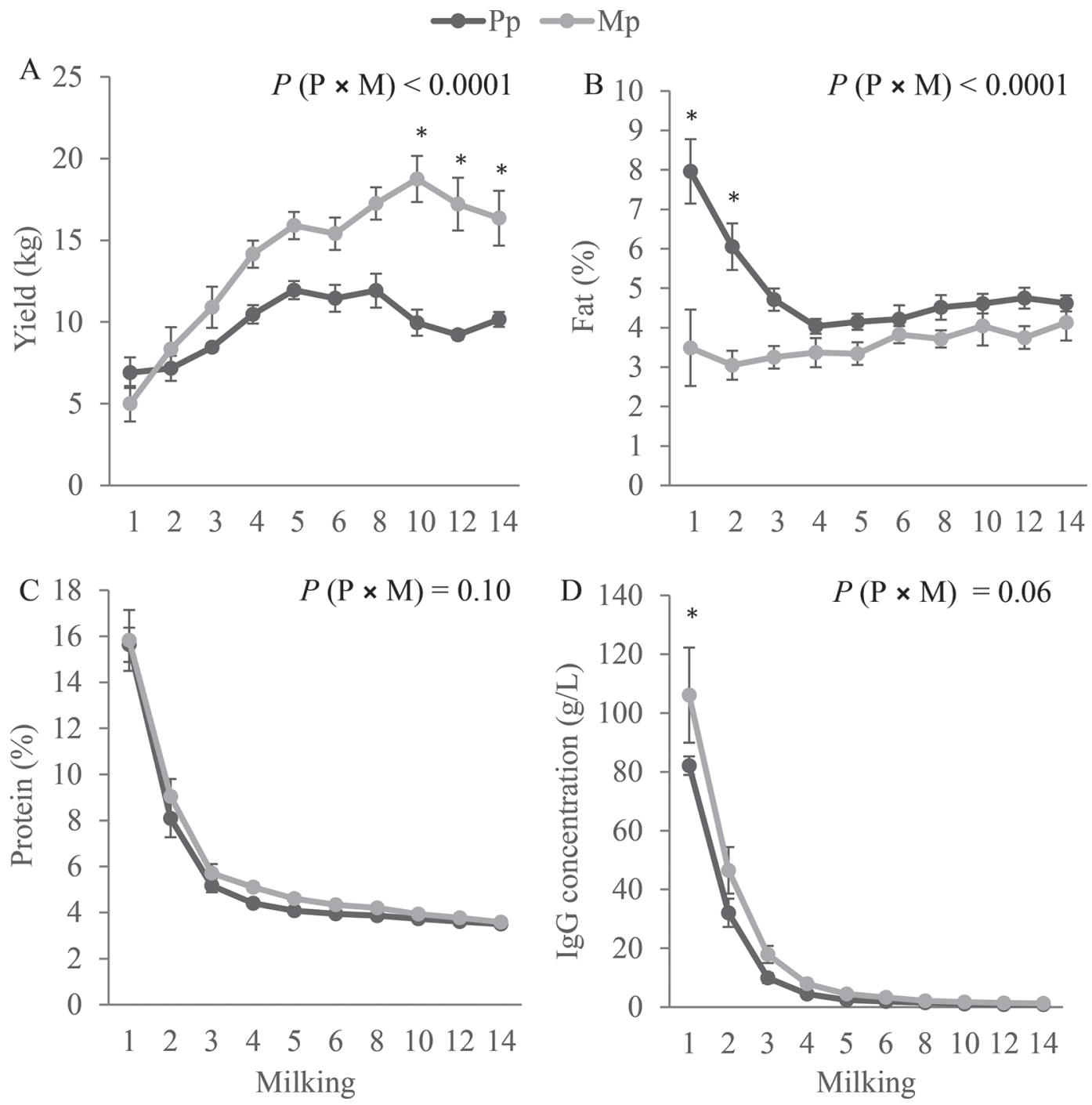

Figure 1. (A) Yield (kg), (B) fat (\%), (C) protein (\%), and (D) IgG concentration (g/L) of multiparous (Mp, $\mathrm{n}=10)$ and primiparous (Pp, $\mathrm{n}=10)$ dairy cows milked twice daily. Data points represent mean \pm SEM. *Significant difference $(P<0.05)$ between Mp and Pp cows within milking $(\mathrm{P} \times \mathrm{M})$. 


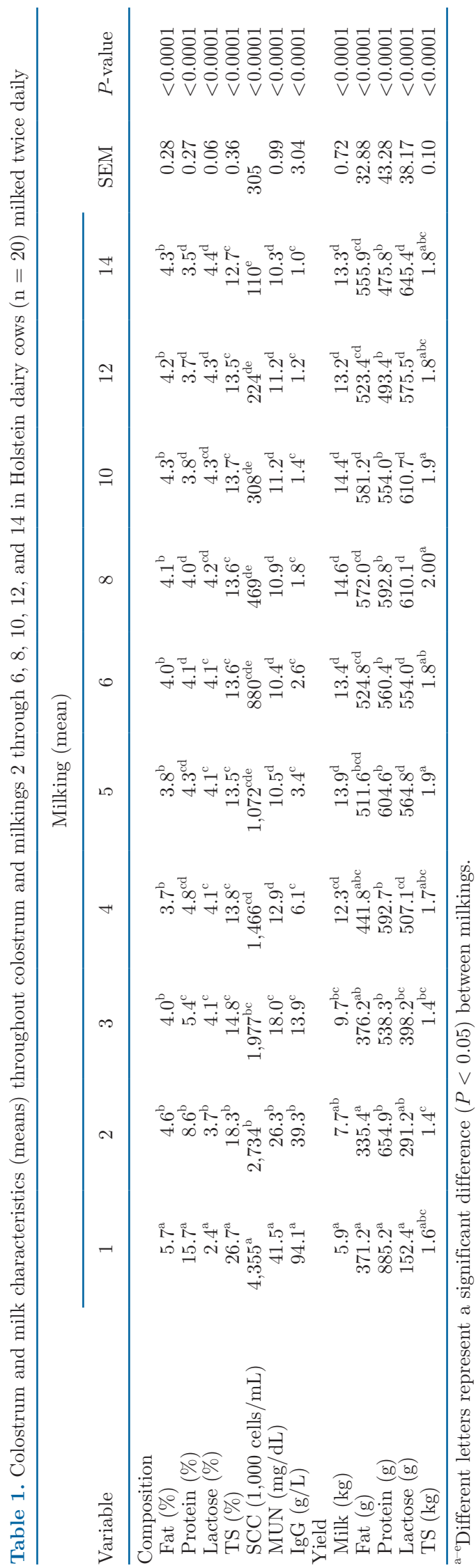

trum had the highest fat percentage compared with all other milkings $(P<0.0001$; Table 1$)$. In addition, $\mathrm{Pp}$ cows had a higher fat percentage than Mp cows in colostrum and milking $2(P<0.0001$; Figure 1B). However, Mp cows had a higher average fat yield $(\mathrm{g})$ per milking compared with Pp cows $(533.9 \pm 19.1$ vs. $450.1 \pm 10.4$ $\mathrm{g})$ over the first 7 DIM $(P=0.03)$. Fat yield was lower in colostrum and milkings 2 and 3 compared with milkings $6+(P<0.0001$; Table 1$)$. Moreover, Pp cows had a higher fat yield in colostrum (Table 2) and a lower fat yield in milking 10 (Supplemental Figure S1A; https: //doi.org/10.3168/jds.2019-17357) compared with Mp cows $(P<0.0001)$.

For protein, colostrum had a higher percentage in colostrum compared with all other milkings $(P<0.0001$; Table 1). No differences were observed for protein percentage between parities or for the interaction between milking and parity (Figure 1C). For protein yield, Mp cows had a higher average protein yield per milking compared with Pp cows over the first 7 DIM (684.3 \pm 17.5 vs. $460.0 \pm 20.9 \mathrm{~g} ; P=0.0002$ ). Regardless of parity, colostrum had the highest protein yield compared with all other milkings $(P<0.0001$; Table 1$)$. In addition, $\mathrm{Pp}$ cows had a higher protein yield in colostrum $(P<0.0001$; Table 2$)$ and a lower protein yield in milking 10 compared with $\mathrm{Mp}$ cows (Supplemental Figure S1B; https://doi.org/10.3168/jds.2019-17357).

Parity had an effect on MUN, with Pp cows having a higher MUN concentration compared with Mp cows $(16.1 \pm 0.8$ vs. $13.6 \pm 0.8 \mathrm{mg} / \mathrm{dL} ; P=0.03)$ on average per milking over the first 7 DIM, yet no effect was observed for the interaction of milking and parity $(P$ $=0.40$ ). Colostrum and milkings 2 and 3 had a higher MUN concentration compared with all other milkings $(P<0.0001$; Table 1$)$.

A difference was observed for IgG between milkings, with the highest concentration of $\operatorname{IgG}$ in colostrum and milking 2 compared with all other milkings $(P<$ 0.0001; Table 1). Specifically, IgG was reduced by $58 \%$ in milking 2 , by $85 \%$ in milking 3 , and by $94 \%$ in milking 4, relative to colostrum. In addition, Mp cows had a higher concentration of IgG in colostrum compared with $\mathrm{Pp}$ cows $(P=0.02$; Figure 1D). No differences were observed for the overall effect of parity $(P=0.06)$ or the interaction between parity and milking $(P=$ $0.06)$.

Although no effect was observed for parity $(P=$ $0.054)$ or the interaction of parity and milking $(P=$ 0.70 ) for lactose percentage, colostrum and milking 2 had a lower lactose percentage compared with all other milkings $(P<0.0001$; Table 1$)$. For lactose yield, Mp cows had a higher yield on average per milking over the first 7 DIM compared with Pp cows (607.0 \pm 21.2 vs. $408.2 \pm 11.0 \mathrm{~g} ; P=0.0006)$. Similar to lactose percent- 
Table 2. Colostrum characteristics between parity

\begin{tabular}{lcccc}
\hline & \multicolumn{2}{c}{ Parity $(\text { mean })^{1}$} & & \\
\cline { 2 - 3 } Variable & $\mathrm{Mp}$ & $\mathrm{Pp}$ & & $\begin{array}{c}P \text {-value: } \\
\mathrm{P} \times \mathrm{M}^{2}\end{array}$ \\
\hline Composition & & & & \\
Fat (\%) & 3.49 & 7.96 & 0.40 & $<0.0001$ \\
Protein (\%) & 15.82 & 15.63 & 0.39 & 1.00 \\
Lactose (\%) & 2.27 & 2.61 & 0.08 & 0.38 \\
TS (\%) & 24.32 & 29.01 & 0.51 & $<0.0001$ \\
SCC (1,000 cells/mL) & $6,021.8$ & $2,697.6$ & 431.9 & $<0.0001$ \\
MUN (mg/dL) & 38.50 & 44.54 & 1.40 & 0.34 \\
IgG (g/L) & 106.1 & 82.1 & 4.31 & 0.02 \\
Component yield & & & & \\
Colostrum yield (kg) & 6.90 & 5.00 & 1.02 & 0.99 \\
Fat (g) & 177.78 & 565.43 & 46.45 & $<0.0001$ \\
Protein (g) & 700.46 & $1,069.17$ & 61.13 & 0.008 \\
Lactose (g) & 124.20 & 179.47 & 54.13 & 1.00 \\
TS yield (kg) & 1.13 & 2.01 & 0.14 & 0.006 \\
\hline
\end{tabular}

${ }^{1}$ Values represent means. $\mathrm{Mp}=$ multiparous cows $(\mathrm{n}=10), \mathrm{Pp}=$ primiparous cows $(\mathrm{n}=10)$.

${ }^{2} \mathrm{P}=$ parity; $\mathrm{M}=$ colostrum milking.

age, colostrum and milkings 2 and 3 had less lactose (g) in comparison with mature milk $(P<0.0001$; Table $1)$. Lactose concentration increased by $35 \%$ from colostrum to milking 2 , and by $41 \%$ from colostrum to milking 3 (Figure 2A). Moreover, Pp cows had a lower lactose yield in milkings 10,12 , and 14 compared with Mp cows $(P<0.0001$; Supplemental Figure S1C; https: //doi.org/10.3168/jds.2019-17357).

For TS percentage, Pp cows had a higher percentage on average per milking than Mp cows $(15.5 \pm 0.4$ vs. $14.4 \pm 0.3 \% ; P=0.003)$ over the first 7 DIM and a higher percentage in colostrum than $\mathrm{Mp}$ cows $(P=$ 0.004; Table 2). Regardless of parity, colostrum and milking 2 had higher TS percentage compared with all other milkings $(P<0.0001$; Table 1$)$. For TS yield $(\mathrm{kg}), \mathrm{Mp}$ cows had higher yield over the first 7 DIM compared with $\mathrm{Pp}$ cows $(2.02 \pm 0.05$ vs. $1.45 \pm 0.03$ $\mathrm{kg} ; P=0.0002)$. Milkings 2 and 3 had lower TS yield compared with milkings 5,8 , and $10(P<0.0001$; Table 1). Moreover, Pp cows had higher TS yield in colostrum $(P<0.0001$; Table 2$)$, yet lower TS yield in milkings 10 and 12, compared with Mp cows (Supplemental Figure S1D; https://doi.org/10.3168/jds.2019-17357).

\section{Oligosaccharide Concentrations}

In a comparison of the OS concentrations $(\mu \mathrm{g} / \mathrm{mL})$, 3'SL had the highest concentration on average per milking over the first 7 DIM compared with all other OS types $\left(3^{\prime} \mathrm{SL}, 145.7 \pm 14.6\right.$ vs. $6^{\prime} \mathrm{SL}, 50.0 \pm 4.1 ; 6^{\prime} \mathrm{SLN}$, $32.3 \pm 4.9 ; \mathrm{DSL}, 48.6 \pm 9.3 \mu \mathrm{g} / \mathrm{mL} ; P<0.0001)$, regardless of milking or parity. In addition, 3 'SL was the most abundant OS in colostrum and milkings 2 and 3 compared with all other OS types $(P<0.0001)$. Impor- tantly, 3'SLN was not detected in any of the samples analyzed and thus is not further included in the results.

For the effect of milking, a difference was observed for all OS (Figure 2B,C). Specifically, the concentrations of 3'SL and 6'SL were the highest in colostrum and milkings 2 and 3 compared with milkings $8+(P<0.0001)$. In particular, the concentration of 3 'SL decreased by $49 \%$ in milking 2 , by $71 \%$ in milking 3 , and by $83 \%$ in milking 4, relative to colostrum. The concentrations of 6'SLN were higher in colostrum and milking 2 compared with all other milkings $(P<0.0001)$, while DSL was only higher in colostrum $(P<0.0001)$. Interestingly, in $2 \mathrm{Mp}$ and $2 \mathrm{Pp}$ cows the concentrations of 6'SL began to increase from milking 2 onward until approximately milking 6 , at which time they began to decrease again. This pattern was not observed for $3^{\prime} \mathrm{SL}, 6^{\prime} \mathrm{SLN}$, or DSL in any individual cows.

With regard to the effect of parity, no differences were observed for $3^{\prime}$ SL $(P=0.12), 6^{\prime}$ SL $(P=0.06)$, or DSL $(P=0.70)$ concentrations. However, Mp cows had a higher 6 'SLN concentration on average per milking over the first 7 DIM compared with Pp cows (46.4 \pm 8.7 vs. $16.9 \pm 3.2 \mu \mathrm{g} / \mathrm{mL} ; P=0.01)$. Last, the interaction of milking and parity had no effect on DSL $(P=$ $1.0)$ or $3^{\prime} \mathrm{SL}(P=0.22)$, yet differences were observed for 6 'SL $(P=0.0001)$. In addition, $\mathrm{Mp}$ cows had a higher $(P<0.0001$; Figure $3 \mathrm{~A})$ concentration of $6^{\prime} \mathrm{SLN}$ in colostrum and milking 2 compared with $\mathrm{Pp}$ cows.

\section{Oligosaccharide Yield}

Over the first 7 DIM, 3'SL had the highest yield on average per milking compared with all other OS (3'SL, $1,277.4 \pm 103.7$ vs. 6 'SL, $577.5 \pm 45.3 ;$ DSL, $403.0 \pm$ 

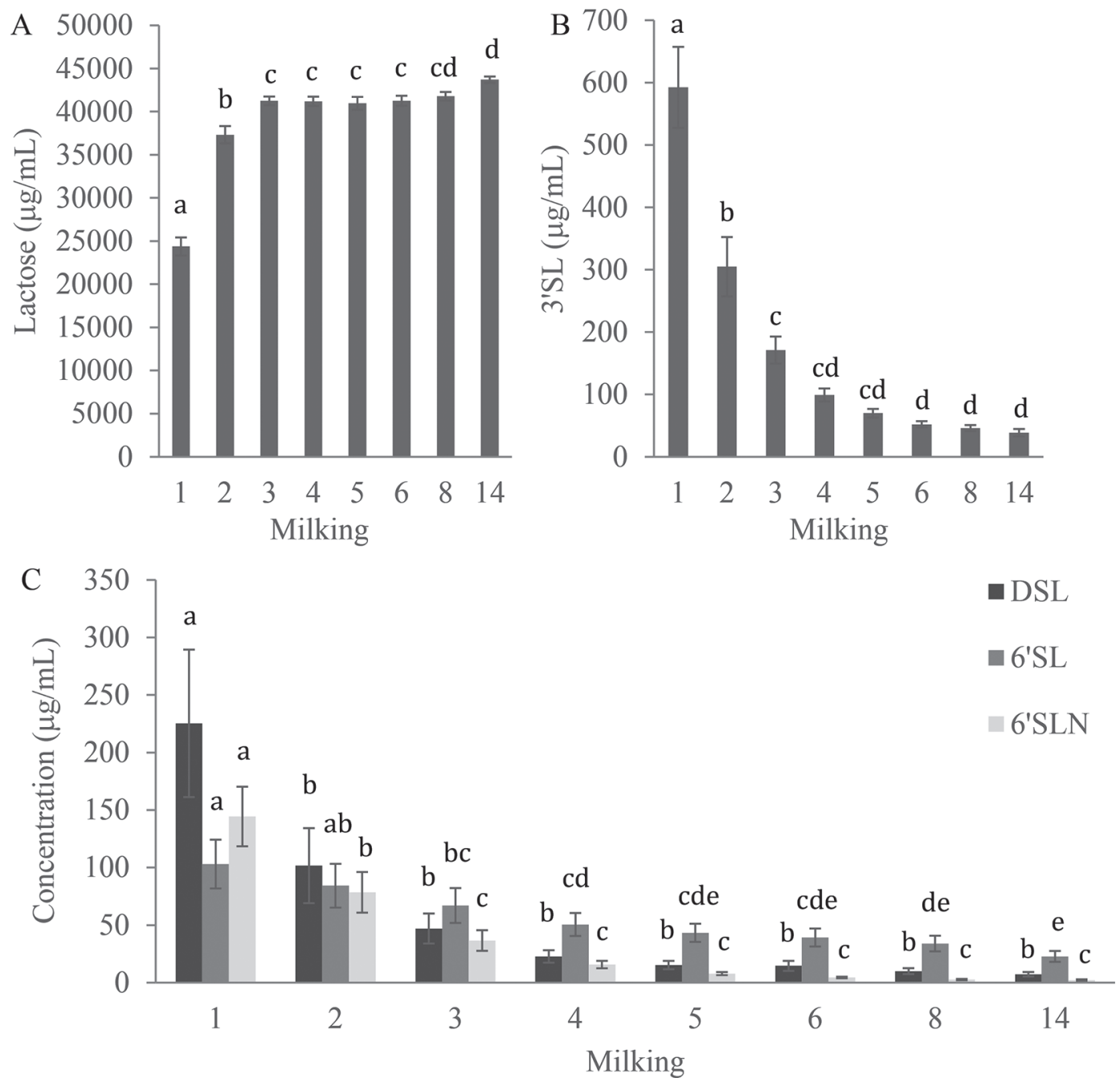

Figure 2. (A) Lactose, (B) 3'-sialyllactose (3'SL), and (C) 6'-sialyllactose (6'SL), 6'-sialyllactosamine (6'SLN), and disialyllactose (DSL) concentrations $(\mu \mathrm{g} / \mathrm{mL})$ in Holstein dairy cows $(\mathrm{n}=20)$ during colostrum, milkings 2 through 6 , 8, and 14 . Bars represent mean \pm SEM. Different letters $(\mathrm{a}-\mathrm{e})$ represent a significant difference $(P<0.05)$ between milkings $(\mathrm{M})$ within each oligosaccharide.

$70.5 ; 6$ 'SLN, $257.8 \pm 38.6 \mathrm{mg} ; P<0.0001$ ), and $6{ }^{\prime} \mathrm{SL}$ had a higher yield compared with $6{ }^{\prime}$ SLN but did not differ from DSL. Moreover, 3'SL had the highest yield in colostrum and milkings 2 and 3 compared with all other OS $(P<0.0001$; Figure 4$)$ and a higher yield than $6^{\prime}$ SLN and DSL in milking 4.

Differences were observed for $3^{\prime} \mathrm{SL}, 6^{\prime} \mathrm{SL}, 6^{\prime} \mathrm{SLN}$, and DSL between milkings. Specifically, 3'SL yield was higher in colostrum and milkings 2 and 3 compared with mature milk $(P<0.0001)$, while 6 'SLN yield was higher in colostrum and milking 2 compared with mature milk $(P<0.0001)$. For DSL, the yield was only higher in colostrum compared with mature milk $(P<$ 0.0001 ), and for 6 'SL, milkings 2,3 , and 4 yield were higher compared with milking $14(P=0.0002)$.

Last, Mp cows had higher ${ }^{\prime}$ SL $(\mathrm{Pp}, 944.7 \pm 107.8$ vs. $\mathrm{Mp}, 1,606.7 \pm 170.9 \mathrm{mg}), 6^{\prime} \mathrm{SL}(\mathrm{Pp}, 284.9 \pm 27.4$

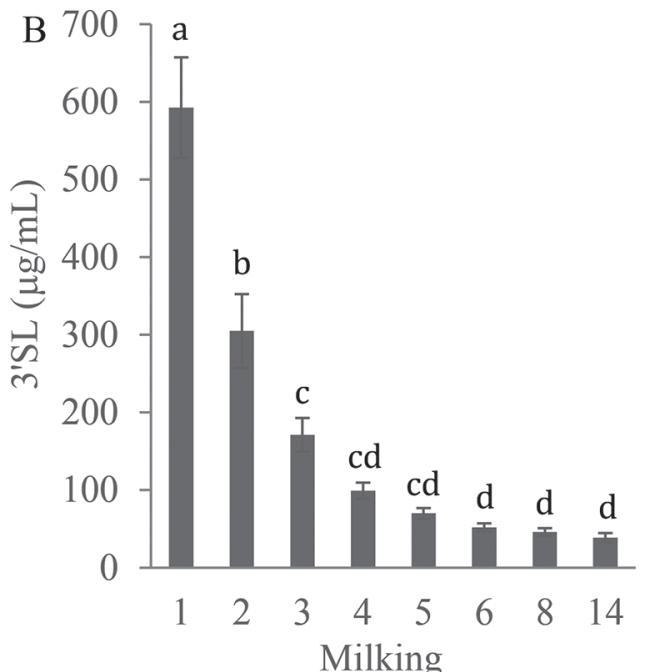

- DSL

- 6'SL

6'SLN

vs. $\mathrm{Mp}, 827.3 \pm 77.1 \mathrm{mg}$ ), and $6^{\prime} \mathrm{SLN}(\mathrm{Pp}, 122.0 \pm 20.0$ vs. Mp, $380.8 \pm 69.0 \mathrm{mg}$ ) yield on average over the first 7 DIM compared with $\mathrm{Pp}$ cows $(P<0.04)$, while no differences were observed between parity for DSL $(P$ $=0.63)$. Although no differences were observed for the interaction of milking and parity for $3^{\prime}$ SL $(P=0.12)$, 6 'SL $(P=0.14)$, and DSL $(P=1.0)$ yield, Mp cows had higher 6 'SLN yield at milking 2 compared with Pp cows $(P=0.0008 ;$ Figure 3B $)$.

\section{DISCUSSION}

Gastrointestinal tract disorders are responsible for $32 \%$ of all deaths and $56 \%$ of all illnesses in dairy calves, with most calves developing clinical signs at or before 2 wk of age (Urie et al., 2018). Therefore, knowledge regarding compounds that may promote 


$$
\rightarrow \mathrm{Pp} \leadsto \mathrm{Mp}
$$
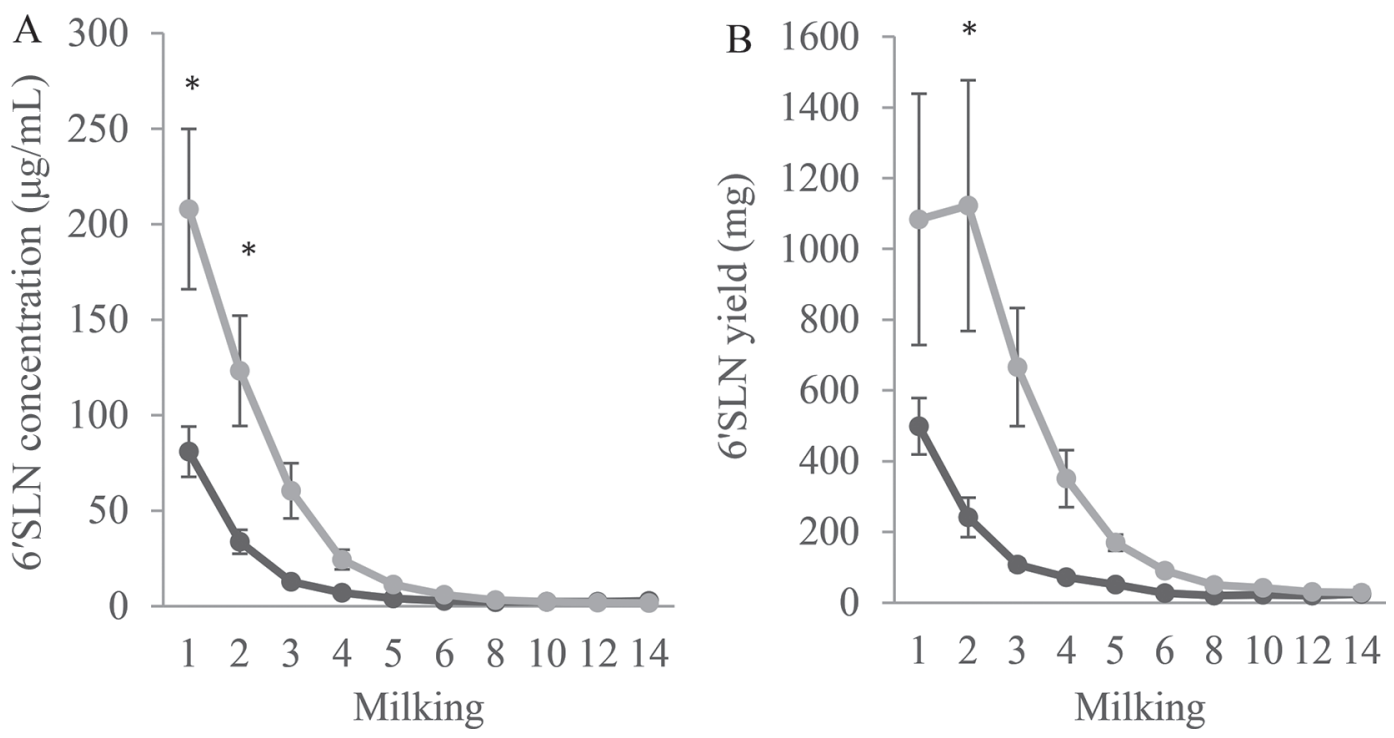

Figure 3. (A) 6'-Sialyllactose (6'SLN) concentration $(\mu \mathrm{g} / \mathrm{mL})$ and $(\mathrm{B}) 6^{\prime} \mathrm{SLN}$ yield $(\mathrm{mg})$ of multiparous $(\mathrm{Mp}, \mathrm{n}=10)$ and primiparous $(\mathrm{Pp}$, $\mathrm{n}=10)$ dairy cows milked twice daily. Bars represent mean \pm SEM. *Significant difference $(P<0.05)$ between Mp and Pp cows within milking $(\mathrm{P} \times \mathrm{M})$.

gut health during early life may potentially decrease these high rates of calf morbidity and mortality in the dairy industry. The objective of the present study was to characterize OS concentrations over the first 7 DIM in $\mathrm{Mp}$ and $\mathrm{Pp}$ cows. To our knowledge, Fischer et al. (2018) were the first to characterize the concentrations of bovine colostrum OS in the calf gut and to demonstrate that high concentrations of OS may mediate the early establishment of beneficial gut bacteria. In the present study, we showed that the concentration of the major sialylated OS, 3'SL, follows a trend similar to fat percentage after calving and is strongly correlated with IgG concentrations $(r=0.80$; Supplemental Table S2; https://doi.org/10.3168/jds.2019-17357). Both fat percentage and $\operatorname{IgG}$ concentration have well-known roles in promoting the health and survival of the neonatal calf (Girard, 1986; Lepine et al., 1991; Weaver et al., 2000), suggesting that 3'SL may also play a role in

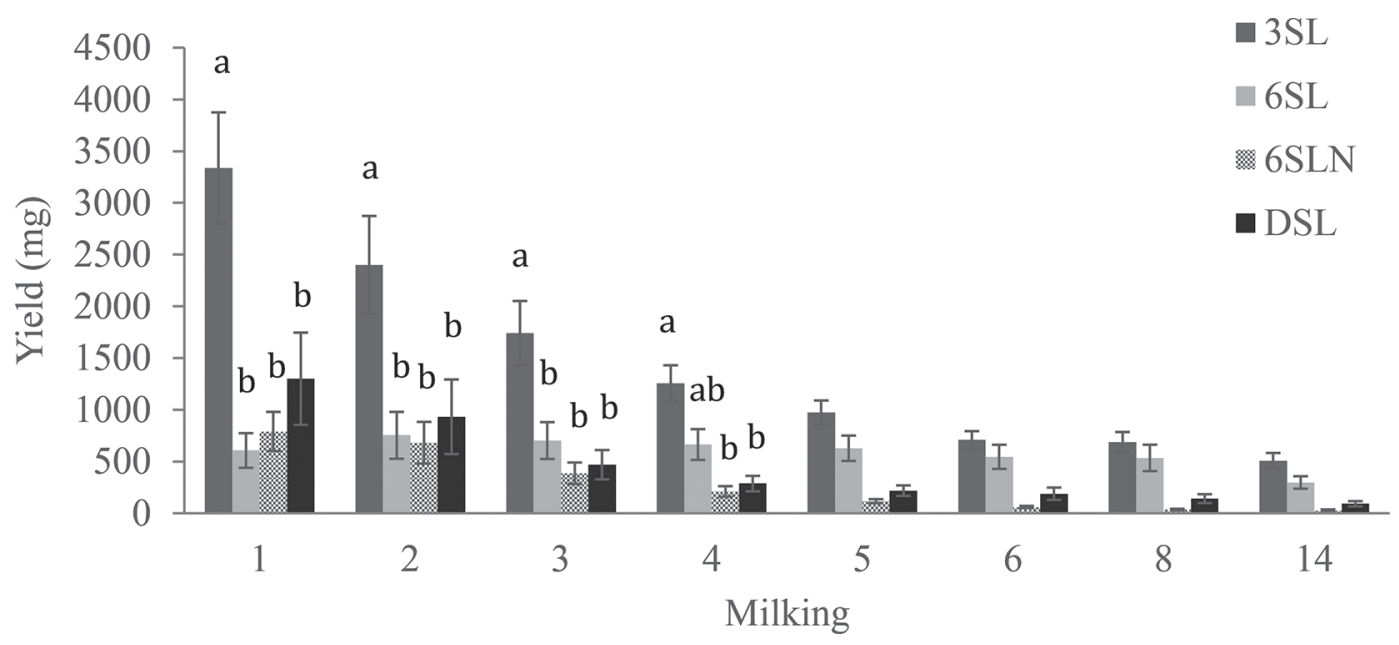

Figure 4. Oligosaccharide yield $(\mathrm{mg})$ in dairy cows $(\mathrm{n}=20)$ in colostrum and milkings 2 to 6 , 8 , and 14 . Bars represent mean \pm SEM for each oligosaccharide. Different letters $(\mathrm{a}, \mathrm{b})$ represent a significant difference $(P<0.05)$ between oligosaccharides within each milking $(\mathrm{M} \times \mathrm{OS})$. $3 \mathrm{SL}=3^{\prime}$-sialyllactose; $6 \mathrm{SL}=6{ }^{\prime}$-sialyllactose; $6 \mathrm{SLN}=6^{\prime}$-sialyllactosamine; DSL $=$ disialyllactose 
newborn health. It is important to note that OS bound to milk fat globules (Gopal and Gill, 2000) or present in the milk fat fraction are not reported because they could not be detected due to the defatting protocol used in this study. Although up to $90 \%$ of OS exist in the carbohydrate fraction (Obermeier et al., 1999), the contribution of milk fat OS to the overall milk OS pool has yet to be determined, and future research should explore milk fat OS and their possible relationship with gut function and development. When the decline of IgG and OS from colostrum to each milking was explored, it was found that the majority of OS followed a similar trend to IgG after calving; however, 3'SL declined in a slower manner from colostrum to milking 3, which may have physiological importance for the immature neonatal GIT. We speculate that the presence of this molecule may help protect calves from pathogenic bacteria and viruses present in their environment (Martín et al., 2002; Hester et al., 2013); however, further research is needed. In addition, OS displayed an opposite trend to that of lactose, in which lactose concentration in colostrum and milking 2 was respectively 44 and $15 \%$ lower than in mature milk. As lactose is the major backbone of all OS, free lactose concentrations may be lower in colostrum and TM because it is being used to contribute to high levels of sialylated OS present during this time. The observed relationships of OS with the major colostral and milk components reinforces their importance as a potential component of bovine colostrum and TM that may promote neonatal calf GIT health.

Our results show the highest concentrations of $3^{\prime} \mathrm{SL}$, 6'SLN, and DSL were present in colostrum compared with all other milkings, with 3 'SL being the most abundant OS in colostrum compared with all other OS. However, considerable variation exists between the colostral 3'SL concentration reported in previous literature (Martín-Sosa et al., 2003; Nakamura et al., 2003; Fischer et al., 2018) and in the present study. As described by Fischer et al. (2018), large differences exist among previous studies regarding sample size, ranging from 1 to 6 animals, as well as sampling time following parturition and the breed and parity of the animals used. McJarrow and van Amelsfort-Schoonbeek (2004) conducted an OS characterization study with 18 Friesian Mp cows and reported a concentration of $681 \mu \mathrm{g} /$ $\mathrm{mL}$ for colostral $3^{\prime} \mathrm{SL}$, which is relatively similar to our reported colostral 3'SL concentration of $592.4 \mu \mathrm{g} / \mathrm{mL}$ from 20 Holstein-Friesian cows. It is important to note the concentrations reported in our study are the first to be based on a sample number of this size while accounting for the influence of OS concentrations during early lactation from $\mathrm{Pp}$ cows. The use of a larger sample size allowed us to observe the high individual variation that existed in colostral OS concentrations. For instance, colostral 3'SL concentrations ranged from 147.0 to $1,149.8 \mu \mathrm{g} / \mathrm{mL}(\mathrm{SD}=290.3 \mu \mathrm{g} / \mathrm{mL})$, DSL from 28.5 to $906.0 \mu \mathrm{g} / \mathrm{mL}(\mathrm{SD}=286.6 \mu \mathrm{g} / \mathrm{mL}), 6^{\prime} \mathrm{SLN}$ from 34.4 to $493.2 \mu \mathrm{g} / \mathrm{mL}(\mathrm{SD}=115.8 \mu \mathrm{g} / \mathrm{mL})$, and $6{ }^{\prime} \mathrm{SL}$ from 22.4 to $370.8 \mu \mathrm{g} / \mathrm{mL}(\mathrm{SD}=94.8 \mu \mathrm{g} / \mathrm{mL})$ among individual cows. Interestingly, when the concentrations of each OS were plotted for individual cows over lactation, a similar result was observed among 4 cows, with $6^{\prime} \mathrm{SL}$ increasing from milking 3 onwards for a varying amount of time for each cow and an oscillating pattern observed in one particular cow. Barile et al. (2010) demonstrated that all cows $(\mathrm{n}=6)$ in their study displayed a consistent pattern, with $6^{\prime}$ SL beginning at a low level at 0 $\mathrm{h}$, increasing after $12 \mathrm{~h}$, following a periodic oscillation for every $24 \mathrm{~h}$, and lasting for the first $60 \mathrm{~h}$ after calving. Research has shown that sialylated OS possess the ability to inhibit pathogenic bacteria, with $\alpha 2,6$-linked sialic acid (6'SL or $6^{\prime}$ SLN) being more efficient than a2,3-linked sialic acid at inhibiting hemagglutination mediated by Escherichia coli adhesin K99 (Newburg, 2000; Martín et al., 2002; LoCascio et al., 2007; Zivkovic et al., 2011). Thus, our results suggest that while IgG concentrations are decreasing, concentrations of $6^{\prime} \mathrm{SL}$ may be increasing to offer additional antimicrobial defense in the first days of life (Martín et al., 2002). However, this result warrants further research, possibly through the use of more frequent (e.g., 6-h interval) sampling after calving.

Typically, 3'SL is the most abundant OS in colostrum and early milkings on average (Nakamura et al., 2003), as was reported in this study; however, this pattern was not observed for certain individual animals. We noted that 1,1 , and $3 \mathrm{Mp}$ cows out of 10 had $6^{\prime} \mathrm{SL}$ as the most abundant OS in colostrum, milking 2, and milking 3, respectively, and that $3 \mathrm{Mp}$ cows had DSL as the most abundant OS in colostrum. This variation has been suggested to be due to the unique genetic variability of the individual, similar to the OS composition of human colostrum and milk (Ninonuevo et al., 2006; Barile et al., 2010). On average, DSL was the second most abundant OS in bovine colostrum, followed by $6^{\prime} \mathrm{SLN}$ and $6^{\prime} \mathrm{SL}$. To our knowledge, the present study and Fong et al. (2011) are the only studies to report DSL as the second most abundant OS; 6 'SLN is typically the second most abundant of all OS measured (Gopal and Gill, 2000; Nakamura et al., 2003; Martín-Sosa et al., 2003; McJarrow and van Amelsfort-Schoonbeek, 2004; Fischer et al., 2018). Barile et al. (2010) found that SLN was only the second most abundant in $5.8 \%$ of samples and that 2 different neutral OS compounds were the second most abundant in 80 and $23 \%$ of samples. These results sug- 
gest 6'SLN may not always be the prevailing OS after $3^{\prime} \mathrm{SL}$, and future research should consider the potential presence of neutral OS in bovine colostrum and milk.

On farm, it is common to feed calves 1 to 2 meals of colostrum, followed by an abrupt transition to whole milk or milk replacer (Vasseur et al., 2010). Despite research demonstrating that TM contains elevated levels of bioactive molecules, hormones, growth factors, and OS (Blum and Hammon, 2000; Nakamura et al., 2003), it is commonly discarded on farm, mostly due to high SCC making TM undesirable for human consumption and the difficulty in managing the feeding of TM to calves. When TM is fed following the colostrum meal, calves have lower odds of being assigned a worse eye/ ear and nasal score (Conneely et al., 2014) and have increased intestinal villi height and greater small intestinal surface area (Pyo et al., 2020) than calves fed whole milk. Research regarding the specific compounds in TM that may contribute to the beneficial effects observed when they are fed to calves is lacking. The results of the present study demonstrate that concentrations of $3^{\prime} \mathrm{SL}$ and 6 'SL were highest in colostrum and milkings 2 and 3 compared with milkings $8+$ and the concentrations of 6 'SLN were higher in colostrum and milking 2 compared with all other milkings, while DSL was only significantly higher in colostrum. The higher concentrations of $3^{\prime} \mathrm{SL}, 6^{\prime} \mathrm{SL}$, and $6{ }^{\prime} \mathrm{SLN}$ in milkings 2 and 3 reinforce the notion that feeding TM to calves may benefit gut health. It is recommended to feed calves colostrum containing $50 \mathrm{~g}$ of $\mathrm{IgG} / \mathrm{L}$ (Weaver et al., 2000) or at least $125 \mathrm{~g}$ of $\operatorname{IgG}$ before $6 \mathrm{~h}$ of life to achieve adequate passive transfer (Osaka et al., 2014); however, the concentrations and quantity of OS required to evoke a physiological response in the calf gut is unknown. In the present study, $6^{\prime} \mathrm{SLN}, 6^{\prime} \mathrm{SL}$, and DSL are only present at concentrations of 103 to $225 \mu \mathrm{g} / \mathrm{mL}$ in colostrum, while 3 'SL does not decrease below this level until after milking 4. Future research should conduct OS supplementation studies at the calf level to determine the threshold OS concentrations required for effective OS bioactivity.

The present study is the first to report OS yield, and the result was similar to that observed for OS concentration between milkings, with a higher yield of ${ }^{\prime}$ 'SL in colostrum and milkings 2 and 3 than in mature milk (milkings 8+) and higher 6'SLN yield in colostrum and milking 2 than in mature milk. Moreover, for $6^{\prime} \mathrm{SL}$, milkings 2 , 3, and 4 were different from milking 14, and DSL yield was only higher in colostrum compared with mature milk. Although the results are similar to that of OS concentration, this parameter is useful to demonstrate OS yield remains greater in TM than in mature milk because it is not affected by dilution. On average, cows produced $5.9 \pm 0.7 \mathrm{~kg}$ of colostrum, of which only 3 to $4 \mathrm{~L}$ would be consumed by the calf in a single feeding. Therefore, although an average of 3.3 $\mathrm{g}$ of 3 'SL was produced in colostrum, only a fraction of this amount may be needed to evoke a beneficial physiological response in the gut of the calf. If $3^{\prime} \mathrm{SL}$ is indeed required, an opportunity may exist for commercial collection for direct supplementation to calves during early life in colostrum, whole milk and colostrum, or milk replacers. Recently, it has been demonstrated that bovine OS can be extracted during cheese whey processing, which is produced in mass amounts each day by major cheese manufacturing companies and has long been discarded (Barile et al., 2009; Aldredge et al., 2013). With these recent advancements in the isolation of bovine OS, the dairy industry may begin to explore the possibility of supplementing OS in calf colostrum or milk replacers to benefit calf health as this field of study advances. Moreover, significant overlap has been reported between bovine colostrum and human milk, with 13 OS in common. This finding has implications for the use of bovine OS in human health-promoting supplements or infant formula (Aldredge et al., 2013).

In addition to observing an effect for milking number, OS yield also differed with parity, with Mp cows having a greater OS yield than $\mathrm{Pp}$ cows, on average, over the first 7 DIM in all OS, except for DSL. Moreover, we also observed a higher concentration of 6'SLN for Mp cows compared with Pp cows. Claps et al. (2016) observed an opposite result in goats, with second-parity goats having a higher concentration of 3'SL compared with third-parity goats, and attributed this difference to the reduced lactose percentage in third-parity animals. However, the authors did not measure the concentration of $6{ }^{\prime} \mathrm{SLN}$, which differs in structure and function from $3^{\prime}$ SL. In addition, a direct comparison between these 2 species is unwarranted due to differences in genetics, production, and nutrition. Although little is known about how parity number in bovine animals may affect OS concentration and yield, OS synthesis in the mammary gland is known to occur by the action of a glycosyltransferase (e.g., sialyltransferase) specific to each molecule (Urashima and Taufik, 2011), which takes place in different compartments of the cell, including the cytosol, nucleus, and Golgi apparatus (Wickramasinghe et al., 2011; Petrosyan et al., 2012). Wickramasinghe et al. (2011) demonstrated that 92 glycosylated-related genes were involved in OS metabolism pathways in bovine somatic cells, which are representative of mammary gland tissue (Cánovas et al., 2014), at d 15 and 250 of lactation. That study demonstrated that the gene expression profiles did not differ between Holstein and Jersey cows but only used 
Mp cows; therefore, no conclusions can be drawn regarding differences in the synthesis of OS in Pp versus Mp cows during early lactation. We hypothesize that Mp cows may have had a higher yield of certain OS and a higher concentration of 6'SLN due to increased mammary gland development compared with Pp cows; however, future research regarding this hypothesis is needed. Aside from the possibility of differing mammary gland development, $\mathrm{Mp}$ and $\mathrm{Pp}$ cows in the present study were also fed different diets prior to $3 \mathrm{wk}$ before calving due to their different nutritional requirements for growth and maintenance. Vicaretti et al. (2018) demonstrated that cows fed distinctly different diets before and during lactation, with one group exclusively grass-fed and the other fed a diet consisting of corn and alfalfa silage, earlage, and grain, did not display any differences in total OS or in the relative levels of OS at calving or at d 1 or wk 1 of lactation. Although this finding is important, we cannot completely discount the effect of the precalving or dry period diet on the OS yield or concentration. These findings highlight the need for future research regarding OS production in the bovine mammary gland and the factors, such as parity and diet, that may control OS synthesis.

Finally, although the objective of this paper was to focus on OS in colostrum and TM as potential beneficial compounds for calf development and health, it is important to state that colostrum and milk OS might also have a potential role in the bovine mammary gland. A study conducted by Zandkarimi et al. (2018) determined that of all potential biomarkers analyzed, 3'SL in serum displayed the largest fold difference $(1,400,306,156$, and $125 \%$-fold change at $21,14,7$, and $0 \mathrm{~d}$ before calving, respectively) between cows with clinical mastitis post calving and control cows during the prepartal transition period. The authors suggested that 3'SL may be increased in the mammary gland of cows with mastitis to fight infection and passively transferred into the serum as a result of pathogen-induced damage of the mammary gland epithelial barrier (Mackenzie and Lascelles, 1968; Hamann and Kromker, 1997). Correlation analysis conducted in the present study determined that 3'SL and 6'SLN concentrations and SCC were moderately correlated $(\mathrm{r}>0.50$; Supplemental Table S2; https://doi.org/10.3168/jds.2019 -17357), indicating that certain OS may be associated with the mammary immune response. In the United States, mastitis affects $24.8 \%$ of cows, making it the most common clinical disease reported (USDA-APHIS, 2014 ), costing approximately $\$ 440$ per case (Kelton et al., 1998; Rollin et al., 2015). Therefore, the potential use of colostrum and milk OS as biomarkers for mastitis and their potential role in mammary gland health provide a potentially valuable area of future research.

\section{CONCLUSIONS}

Over the first 7 DIM, Holstein-Friesian cows had greater concentrations of $3^{\prime} \mathrm{SL}$ and $6^{\prime} \mathrm{SL}$ in colostrum and milkings 2 and 3 than in mature milk (milkings $8+$ ) and greater concentrations of 6 'SLN in colostrum and milking 2 than in mature milk, while DSL was only significantly higher in colostrum. These results demonstrate that TM contains elevated concentrations of certain OS compared with mature milk. Future research should explore the possible beneficial effects of OS in colostrum and TM at the calf level, as well as determine the concentrations of OS required to evoke a beneficial physiological response in the GIT of the young calf. In addition, our findings demonstrate that OS levels exhibit similar relationships to other major colostral and milk components, such as IgG and lactose, thus highlighting its importance as a potential bioactive compound in colostrum and TM. The present study characterized OS yield, which demonstrated that Mp cows had a greater OS yield for all OS over the first 7 DIM than Pp cows, except for DSL. As this study is the first to analyze the effect of parity in bovine animals on OS yield and concentrations, we suggest that this result is due to increased mammary gland development in Mp cows compared with Pp cows, but further research regarding the factors that may control OS synthesis and concentrations at the cow level is needed.

\section{ACKNOWLEDGMENTS}

The authors are grateful for the funding support provided by Alberta Livestock and Meat Agency Ltd. (Edmonton, AB, Canada), The Saskatoon Colostrum Co. Ltd. (Saskatoon, SK, Canada), Alberta Milk (Edmonton, AB, Canada), SaskMilk (Regina, SK, Canada), BC Dairy Association (Burnaby, BC, Canada), Dairy Farmers of Manitoba (Winnipeg, MB, Canada), Trouw Nutrition (Guelph, ON, Canada), Bayer Animal Health (Mississauga, ON, Canada), and the Natural Sciences and Engineering Research Council of Canada (Ottawa, ON). The authors also thank the staff at Breevliet Ltd. (Millet, AB, Canada) for their assistance with the collection of samples, L. Nikolai and Y. Zhao (University of Alberta, Edmonton, AB, Canada) for their assistance with LC-MS laboratory analysis, as well as the Saskatoon Colostrum Co. Ltd. for conducting radial immunodiffusion analysis. The authors have not stated any conflicts of interest.

\section{REFERENCES}

Aldredge, D. L., M. R. Geronimo, S. Hua, C. C. Nwosu, C. B. Lebrilla, and D. Barile. 2013. Annotation and structural elucidation of bovine milk oligosaccharides and determination of novel fucosylated 
structures. Glycobiology 23:664-676. https://doi.org/10.1093/ glycob/cwt007.

Barile, D., N. Tao, C. B. Lebrilla, J. D. Coisson, M. Arlorio, and J. B. German. 2009. Permeate from cheese whey ultrafiltration is a source of milk oligosaccharides. Int. Dairy J. 19:524-530. https:// doi.org/10.1016/j.idairyj.2009.03.008.

Barile, D., M. Marotta, C. Chu, R. Mehra, R. Grimm, C. B. Lebrilla, and J. B. German. 2010. Neutral and acidic oligosaccharides in Holstein-Friesian colostrum during the first 3 days of lactation measured by high performance liquid chromatography on a microfluidic chip and time-of-flight mass spectrometry. J. Dairy Sci. 93:3940-3949. https://doi.org/10.3168/jds.2010-3156.

Blum, J. W., and H. Hammon. 2000. Colostrum effects on the gastrointestinal tract, and on nutritional, endocrine and metabolic parameters in neonatal calves. Livest. Prod. Sci. 66:151-159. https: //doi.org/10.1016/S0301-6226(00)00222-0.

Cánovas, A., G. Rincón, C. Bevilacqua, A. Islas-Trejo, P. Brenaut, R. C. Hovey, M. Boutinaud, C. Morgenthaler, M. K. VanKlompenberg, P. Martin, and J. F. Medrano. 2014. Comparison of five different RNA sources to examine the lactating bovine mammary gland transcriptome using RNA sequencing. Sci. Rep. 4:5297. https://doi.org/10.1038/srep05297.

CCAC (Canadian Council on Animal Care). 1993. Guide to the Care and Use of Experimental Animals. Vol. 1. E. D. Olfert, B. M. Cross, and A. A. McWilliams, ed. Canadian Council on Animal Care, Ottawa, ON, Canada.

Chelack, B. J., P. S. Morley, and D. M. Haines. 1993. Evaluation of methods for dehydration of bovine colostrum for total replacement of normal colostrum in calves. Can. Vet. J. 34:407-412.

Claps, S., M. A. Di Napoli, A. R. Caputo, D. Rufrano, L. Sepe, and A. Di Trana. 2016. Factors affecting the $3^{\prime}$ sialyllactose, $6^{\prime}$ sialyllactose and disialyllactose content in caprine colostrum and milk: Breed and parity. Small Rumin. Res. 134:8-13. https://doi.org/10 1016/j.smallrumres.2015.11.002.

Conneely, M., D. P. Berry, J. P. Murphy, I. Lorenz, M. L. Doherty, and E. Kennedy. 2014. Effect of feeding colostrum at different volumes and subsequent number of transition milk feeds on the serum immunoglobulin $\mathrm{G}$ concentration and health status of dairy calves. J. Dairy Sci. 97:6991-7000. https://doi.org/10.3168/jds.2013-7494.

Fischer, A. J., N. Malmuthuge, L. L. Guan, and M. A. Steele. 2018. Short communication: The effect of heat treatment of bovine colostrum on the concentration of oligosaccharides in colostrum and in the intestine of neonatal male Holstein calves. J. Dairy Sci. 101:401-407. https://doi.org/10.3168/jds.2017-13533.

Fong, B., K. Ma, and P. McJarrow. 2011. Quantification of bovine milk oligosaccharides using liquid chromatography-selected reaction monitoring-mass spectrometry. J. Agric. Food Chem. 59:9788 9795. https://doi.org/10.1021/jf202035m.

Gill, R. K., S. Mahmood, J. P. Nagpaul, and A. Mahmood. 1999 Functional role of sialic acid in IgG binding to microvillus membranes in neonatal rat intestine. Biol. Neonate 76:55-64. https:// doi.org/10.1159/000014131.

Girard, J. 1986. Gluconeogenesis in late fetal and early neonatal life. Biol. Neonate 50:237-258. https://doi.org/10.1159/000242605.

Godden, S. 2008. Colostrum management for dairy calves. Vet. Clin. North Am. Food Anim. Pract. 24:19-39. https://doi.org/10.1016/ j.cvfa.2007.10.005

Gopal, P. K., and H. S. Gill. 2000. Oligosaccharides and glycoconjugates in bovine milk and colostrum. Br. J. Nutr. 84(Suppl. 1):S69S74. https://doi.org/10.1017/S0007114500002270.

Hamann, J., and V. Kromker. 1997. Potential of specific milk composition variables for cow health management. Livest. Prod. Sci. 48:201-208. https://doi.org/10.1016/S0301-6226(97)00027-4.

Hester, S. N., X. Chen, M. Li, M. H. Monaco, S. S. Comstock, T. B. Kuhlenschmidt, M. S. Kuhlenschmidt, and S. M. Donovan. 2013 Human milk oligosaccharides inhibit rotavirus infectivity in vitro and in acutely infected piglets. Br. J. Nutr. 110:1233-1242. https: //doi.org/10.1017/S0007114513000391.

Kelton, D. F., K. D. Lissemore, and R. E. Martin. 1998. Recommendations for recording and calculating the incidence of selected clinical diseases of dairy cattle. J. Dairy Sci. 81:2502-2509. https://doi .org/10.3168/jds.S0022-0302(98)70142-0.

Lepine, A. J., R. D. Boyd, and D. M. Whitehead. 1991. Effect of colostrum intake on hepatic gluconeogenesis and fatty acid oxidation in the neonatal pig. J. Anim. Sci. 69:1966-1974. https://doi.org/ $10.2527 / 1991.6951966 \mathrm{x}$.

LoCascio, R. G., M. R. Ninonuevo, S. L. Freeman, D. A. Sela, R. Grimm, C. B. Lebrilla, D. A. Mills, and J. B. German. 2007. Glycoprofiling of bifidobacterial consumption of human milk oligosaccharides demonstrates strain specific, preferential consumption of small chain glycans secreted in early human lactation. J. Agric. Food Chem. 55:8914-8919. https://doi.org/10.1021/jf0710480.

Mackenzie, D. D. S., and A. K. Lascelles. 1968. The transfer of $\left.{ }^{131} \mathrm{I}\right]$ labelled immunoglobulins and serum albumin from blood into milk of lactating ewes. Aust. J. Exp. Biol. Med. Sci. 46:285-294. https: //doi.org/10.1038/icb.1968.23.

Martín, M.-J., S. Martín-Sosa, and P. Hueso. 2002. Binding of milk oligosaccharides by several enterotoxigenic Escherichia coli strains isolated from calves. Glycoconj. J. 19:5-11. https://doi.org/10 $.1023 / \mathrm{A}: 1022572628891$

Martín-Sosa, S., M. J. Martín, L. A. Garcia-Pardo, and P. Hueso. 2003. Sialyloligosaccharides in human and bovine milk and in infant formulas: Variations with the progression of lactation. J. Dairy Sci. 86:52-59. https://doi.org/10.3168/jds.S0022-0302(03)73583-8.

McJarrow, P., and J. van Amelsfort-Schoonbeek. 2004. Bovine sialyl oligosaccharides: Seasonal variation in their concentrations in milk and a comparison of the colostrums of Jersey and Friesian cows. Int. Dairy J. 14:571-579. https://doi.org/10.1016/j.idairyj.2003.11 .006 .

Nakamura, T., H. Kawase, K. Kimura, Y. Watanabe, M. Ohtani, I. Arai, and T. Urashima. 2003. Concentrations of sialyloligosaccharides in bovine colostrum and milk during the prepartum and early lactation. J. Dairy Sci. 86:1315-1320. https://doi.org/10.3168/jds .S0022-0302(03)73715-1.

Newburg, D. S. 2000. Oligosaccharides in human milk and bacterial colonization. J. Pediatr. Gastroenterol. Nutr. 30(Suppl 2):S8-S17. https://doi.org/10.1097/00005176-200003002-00003.

Ninonuevo, M. R., Y. Park, H. Yin, J. Zhang, R. E. Ward, B. H. Clowers, J. B. German, S. L. Freeman, K. Killeen, R. Grimm, and C. B. Lebrilla. 2006. A strategy for annotating the human milk glycome. J. Agric. Food Chem. 54:7471-7480. https://doi.org/10 $.1021 /$ jf0615810.

Obermeier, S., S. Rudloff, G. Pohlentz, M. J. Lentze, and C. Kunz, 1999. Secretion of ${ }^{13} \mathrm{C}$-labelled oligosaccharides into human milk and infant's urine after an oral $\left.{ }^{13} \mathrm{C}\right]$-galactose load. Isotopes Environ. Health Stud. 35:119-125. https://doi.org/10.1080/ 10256019908234084.

Osaka, I., Y. Matsui, and F. Terada. 2014. Effect of the mass of immunoglobulin $(\mathrm{Ig}) \mathrm{G}$ intake and age at first colostrum feeding on serum IgG concentration in Holstein calves. J. Dairy Sci. 97:66086612. https://doi.org/10.3168/jds.2013-7571.

Petrosyan, A., M. F. Ali, and P.-W. Cheng. 2012. Glycosyltransferasespecific Golgi-targeting mechanisms. J. Biol. Chem. 287:3762137627. https://doi.org/10.1074/jbc.C112.403006.

Pyo, J., K. Hare, S. Pletts, Y. Inabu, D. Haines, T. Sugino, L. L. Guan, and M. Steele. 2020. Feeding colostrum or a 1:1 colostrum: milk mixture for 3 days postnatal increases small intestinal development and minimally influences plasma GLP-2 and serum insulin-like growth factor-1 concentrations in Holstein bull calves. J. Dairy Sci. https://doi.org/10.3168/jds.2019-17219.

Rollin, E., K. C. Dhuyvetter, and M. W. Overton. 2015. The cost of clinical mastitis in the first 30 days of lactation: An economic modelling tool. Prev. Vet. Med. 122:257-264. https://doi.org/10.1016/j .prevetmed.2015.11.006.

Short, D. M., D. A. Moore, and W. M. Sischo. 2016. A randomized clinical trial evaluating the effects of oligosaccharides on transfer of passive immunity in neonatal dairy calves. J. Vet. Intern. Med. 30:1381-1389. https://doi.org/10.1111/jvim.13949.

Sohanpal, B. K., S. El-Labany, M. Lahooti, J. A. Plumbridge, and I. C. Blomfield. 2004. Integrated regulatory responses of fimB to 
$\mathrm{N}$-acetylneuraminic (sialic) acid and GlcNAc in Escherichia coli K-12. Proc. Natl. Acad. Sci. USA 101:16322-16327. https://doi .org/10.1073/pnas.0405821101.

Sundekilde, U. K., A. Barile, M. Meyrand, N. A. Poulsen, L. B. Larsen, C. B. Lebrilla, J. B. German, and H. C. Bertram. 2012. Natural variability in bovine milk oligosaccharides from Danish Jersey and Holstein-Friesian breeds. J. Agric. Food Chem. 60:6188-6196. https://doi.org/10.1021/jf300015j.

Tao, N., E. J. DePeters, S. Freeman, J. B. German, R. Grimm, and C. B. Lebrilla. 2008. Bovine milk glycome. J. Dairy Sci. 91:3768-3778. https://doi.org/10.3168/jds.2008-1305.

Tao, N., E. J. DePeters, J. B. German, R. Grimm, and C. B. Lebrilla. 2009. Variations in bovine milk oligosaccharides during early and middle lactation stages analyzed by high-performance liquid chromatography-chip/mass spectrometry. J. Dairy Sci. 92:2991-3001. https://doi.org/10.3168/jds.2008-1642.

Urashima, T., and E. Taufik. 2011. Oligosaccharides in milk: Their benefits and future utilization. J. Anim. Sci. Technol. 33:189-197.

Urie, N. J., J. E. Lombard, C. B. Shivley, C. A. Kopral, A. E. Adams, T. J. Earleywine, J. D. Olson, and F. B. Garry. 2018. Preweaned heifer management on US dairy operations: Part V. Factors associated with morbidity and mortality in preweaned dairy heifer calves. J. Dairy Sci. 101:9229-9244. https://doi.org/10.3168/jds .2017-14019.

USDA-APHIS. 2014. Dairy 2014: Milk quality, milking procedures, and mastitis on U.S. Dairies, 2014. Accessed Oct. 11, 2019. https: //www.aphis.usda.gov/animal_health/nahms/dairy/downloads / dairy14/Dairy14_dr_Mastitis.pdf.

Vasseur, E., F. Borderas, R. I. Cue, D. Lefebvre, D. Pellerin, J. Rushen, K. M. Wade, and A. M. de Passillé. 2010. A survey of dairy calf management practices in Canada that affect animal welfare. J. Dairy Sci. 93:1307-1315. https://doi.org/10.3168/jds.2009-2429.

Vicaretti, S. D., N. A. Mohtarudin, A. M. Garner, and W. F. Zandberg. 2018. Capillary electrophoresis analysis of bovine milk oligosaccharides permits and assessment of the influence of diet and the discovery of nine abundant sulfated analogues. J. Agric. Food Chem. 66:8574-8583. https://doi.org/10.1021/acs.jafc.8b01041.

Weaver, D. M., J. W. Tyler, D. C. VanMetre, D. E. Hostetler, and G. M. Barrington. 2000. Passive transfer of colostral immunoglobulins in calves. J. Vet. Intern. Med. 14:569-577. https://doi.org/10 $.1111 /$ j.1939-1676.2000.tb02278.x.

Wickramasinghe, S., S. Hua, G. Rincon, A. Islas-Trejo, J. B. German, C. B. Lebrilla, and J. F. Medrano. 2011. Transcriptome profiling of bovine milk oligosaccharide metabolism genes using RNAsequencing. PLoS One 6:e18895. https://doi.org/10.1371/journal pone.0018895.

Yu, Z.-T., C. Chen, and D. S. Newburg. 2013. Utilization of major fucosylated and sialylated human milk oligosaccharides by isolated human gut microbes. Glycobiology. 23:1281-1292. https://doi.org/ 10.1093 /glycob/cwt065.

Zandkarimi, F., J. Vanegas, X. Fern, C. S. Maier, and G. Bobe. 2018. Metabotypes with elevated protein and lipid catabolism and inflammation precede clinical mastitis in prepartal transition dairy cows. J. Dairy Sci. 101:5531-5548. https://doi.org/10.3168/jds 2017-13977.

Zivkovic, A. M., J. B. German, C. B. Lebrilla, and D. A. Mills. 2011. Human milk glycobiome and its impact on the infant gastrointestinal microbiota. Proc. Natl. Acad. Sci. USA 108(Suppl. 1):46534658. https://doi.org/10.1073/pnas.1000083107. 